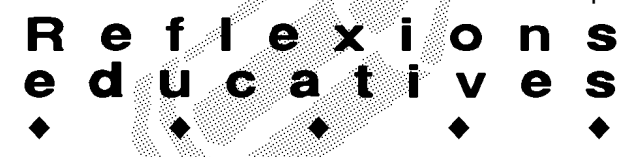

\title{
ELS PROBLEMES SOCIOECONÒMICS I LA SALUT MENTAL EN ELS INFANTS. QUĖ PODEM FER DES DE L'ESCOLA?
}

\author{
Noemí Guillamón Cano. Estudis de Psicologia i Ciències de l'Educació. Universitat Oberta de Catalunya
}

A la nostra vida quotidiana hem de fer front a moltes dificultats: problemes a la feina, problemes de parella, separacions, morts de persones properes, problemes econòmics, etc. Sens dubte, aquests problemes ens afecten en major o menor grau i constitueixen fonts d'estrès que poden alterar el nostre estat d'ànim $i$, en conseqüència, afectar les nostres relacions amb les persones que tenim al voltant.

En aquest treball tractarem com aquests estressors afecten la relació que mantenim amb la família, fent especial èmfasi en com aquests problemes "dels grans" afecten els més petits. Concretament, parlarem de com els problemes econòmics que poden afectar les famílies són viscuts pels nens, i de què podem fer des de l'escola per detectar aquestes dificultats i participar en la mesura que sigui possible per minimitzar-ne l'impacte en aquest grup d'edat.

Comentarem els resultats d'una tesi doctoral presentada l'any 2003 que descriu com la dinàmica familiar es pot veure afectada per estressors de tipus econòmic, $i$ de com aquesta afectació en el funcionament de la família pot influir en la salut mental dels nens.

Semblaria que un treball de fa cinc anys no és prou actual per ser comentat en aquests moments, però des del nostre punt de vista els resultats d'aquesta tesi són de màxima actualitat, ja que ens trobem en un moment de crisi econòmica que fa que moltes famílies pateixin dificultats econòmiques com les que comentarem. L'indicador més emprat als estudis sobre la relació entre els problemes econòmics i la salut mental és el nivell de pobresa, indicador calculat a partir de la ràtio entre els ingressos familiars i el nombre de membres de la família, i que estableix el percentatge de persones que es troben per sota del nivell mitjà d'ingressos en una comunitat determinada. Segons l'Enquesta de condicions de vida (ECV) del 2007 de l'Institut Nacional d'Estadística (2008), l'any 2007 el 19,7\% de les persones se situava per sota del llindar de pobresa. Tanmateix, aquestes xifres, alarmants per si soles, potser ens semblen allunyades de la nostra realitat quotidiana. Una anàlisi més fina que tingui en compte altres indicadors diferents del llindar de pobresa ens informarà que els problemes socioeconòmics no constitueixen un "mal major" que perjudica només una minoria. Per desgràcia, moltes famílies es veuen afectades en major o menor grau per aquestes dificultats. Així, l'Enquesta de població activa (EPA) que cada any realitza l'Institut Nacional d'Estadística assenyala que en el tercer trimestre del 2008 l'11,33\% de la població activa a Espanya es troba desocupada, i que el nombre de persones a l'atur ha augmentat respecte de l'any anterior, especialment entre els homes i en el grup de 25 a 54 anys. No cal anar gaire lluny per assabentar-se de la presència d'expedients de regulació que afecten molts treballadors de grans empreses, que d'un dia per altre es queden sense feina, fet que sens dubte queda recollit a l'enquesta del CIS que va ser comentada fa uns mesos als diaris, on es reflecteix que la principal preocupació dels espanyols en aquests moments és l'atur i els problemes econòmics (EUROPA PRESS, 2008).

Com afecta aquest context social i econòmic les famílies? I quin és l'impacte en els nens? Intentarem donar algunes idees sobre aquests aspectes.

\section{Les dificultats socioeconòmiques i la salut mental dels nens: un model teòric}

Els problemes socioeconòmics poden afectar el nen a través de mecanismes diferents. La revisió de la literatura suggereix que bàsicament hi ha quatre grans grups: la salut i l'accés a recursos externs a la família, l'ambient físic, l'estimulació ambiental i la interacció familiar. Aquests mecanismes són mútuament interdependents i poden intervenir en la relació entre problemes socioeconòmics $\mathrm{i}$ el funcionament socioemocional i cognitiu i el rendiment escolar del nen. La figura 1 mostra esquemàticament aquests quatre mecanismes.

Diversos estudis consideren que un nivell socioeconòmic (SES) baix o la pobresa afecten la salut física del nen. Per exemple, alguns treballs documenten la relació existent entre SES i el desenvolupament prenatal i perinatal del nen, un baix pes en néixer i diferents malalties físiques (BRADLEY i CORWYN, 2002). D'altra banda, les famílies amb baixos ingressos tenen menys accés a 


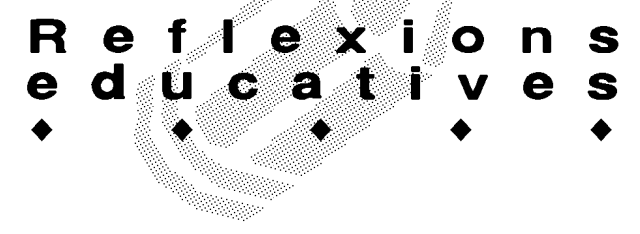

recursos sanitaris i a béns i serveis essencials per a la salut. Aquestes limitacions s'han associat principalment a problemes de salut física en el nen, però també a un funcionament cognitiu i un rendiment escolar baixos (MCLOYD, 1998).

Un nombre elevat de persones vivint a casa (terme conegut com a overcrowding) i unes condicions d'habitatge inadequades poden suposar un obstacle per al desenvolupament del nen. Es considera que aquesta alteració de l'ambient físic pot afectar la resta de mecanismes i comprometre l'adaptació psicològica dels membres de la família (PARK et al., 2002). D’altra banda, la inseguretat del barri i la falta de recursos adequats per als nens (parcs, guarderies, biblioteques, centres esportius, etc.) també poden estar relacionats amb el desenvolupament de problemes de comportament, depressió i ansietat, menor funcionament cognitiu i un rendiment acadèmic més baix.

L'estimulació ambiental que el nen rep a casa, a l'escola o en altres contextos influeix sense cap dubte en el desenvolupament de les seves competències cognitives i en el rendiment acadèmic. Les famílies amb pocs recursos econòmics veuen limitades les seves possibilitats de proporcionar al nen bones escoles, activitats extraescolars o un ambient estimulant a casa (llibres, música, joguines) o de realitzar activitats de lleure que puguin enriquir la seva formació (museus, viatges, teatre). D’altra banda, l'accés a diferents serveis educatius (guarderies, centres esportius, cursos i altres activitats extraescolars) pot incrementar la competència social del nen i reduir la possibilitat que aquest desenvolupi problemes de comportament (DUNCAN i BROOKS-GUNN, 2000).

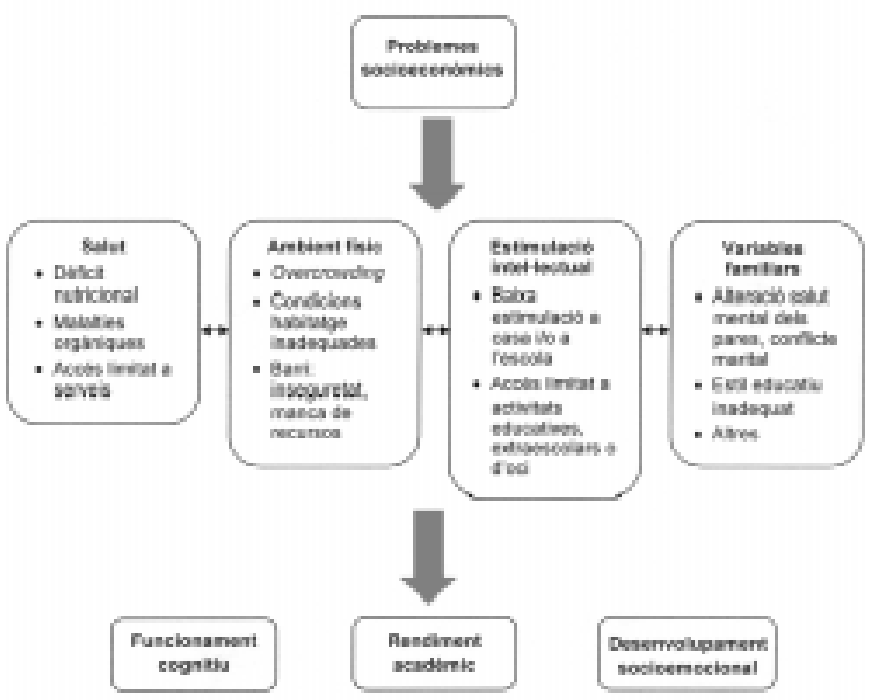

Figura 1. Mecanismes causals (modificada de PARK, TURNBULL $i$ RUTHERFORD, 2002)
Els problemes socioeconòmics també poden afectar el nen a través de l'alteració de la dinàmica familiar. Es considera que la pobresa o un SES baix poden impactar sobre l'estat d'ànim dels pares, la seva relació de parella i/o la interacció amb els fills. Aquest mecanisme s'ha vist relacionat especialment amb el desenvolupament socioemocional del nen, però també amb el seu rendiment acadèmic i funcionament cognitiu.

Aquest treball se centra en l'estudi de l'impacte dels problemes socioeconòmics en la salut mental dels nens a través de l'alteració de la dinàmica familiar. Per això, s'ha pres com a referent un model teòric molt estudiat als Estats Units pel grup de Conger (CONGER, CONGER, ELDER, LORENZ, SIMONS, i WHITBECK, 1992, 1993; CONGER, GE, ELDER, LORENZ i SIMONS, 1994), que exposarem breument a continuació.

Els problemes socioeconòmics afecten els pares principalment alterant-los l'estat emocional: se senten pressionats i preocupats per la seva situació econòmica, tristos i irritables, desesperançats o frustrats. L'alteració del seu estat d'ànim influeix en les relacions que estableixen amb les persones que tenen al seu voltant. En aquest model, es considera que un estat d'ànim deprimit o irritable en algun dels pares pot afectar la relació de la parella i augmentar el grau de discòrdia marital. Al seu torn, les discussions, baralles i mala relació entre els pares poden afectar la forma com es relacionen amb els fills. Els pares amb problemes psicològics i/o mala relació marital poden adoptar un estil educatiu caracteritzat per una disciplina dura, hostil i inconsistent, i un baix nivell de supervisió i d'implicació emocional vers els fills.

En aquest treball es va examinar la contribució de dues d'aquestes dimensions d'estil educatiu: la falta de supervisió i la baixa implicació emocional. La supervisió fa referència al grau en el qual els pares coneixen i controlen les activitats dels fills. Un nivell de supervisió baix indica, per exemple, que els pares no coneixen els amics dels fills, freqüentment no saben on ni amb qui són ni què fan quan estan fora de casa, no estan pendents dels deures de l'escola, del rendiment o de si tenen problemes a la classe. La implicació emocional fa al-lusió al nivell d'interès dels pares en les activitats, preocupacions i interessos dels fills, al grau en què li expressen afecte, acceptació i confiança, a la freqüència amb què el reforcen i li fan comentaris positius o crítics. En aquest sentit, una baixa implicació emocional implica desinterès dels pares cap als fills, i poques o nul-les demostracions d'afecte i d'acceptació. Aquestes dimensions d'estil educatiu s'han relacionat tant amb problemes exterioritzats (problemes de comportament, ús de substàncies, delinqüència) com interioritzats (ansietat i depressió).

L'autoestima fa referència al grau en què l'individu 


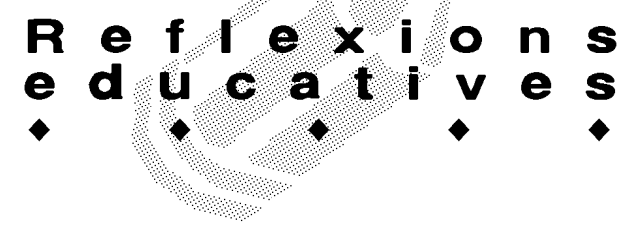

s'accepta a si mateix. Una persona amb una autoestima elevada considera que mereix respecte per part dels altres i avalua positivament el que és i el que fa. En canvi, una persona amb un nivell d'autoestima baix no s'agrada a si mateixa, i es veu de forma inadequada, menyspreable o no digna de respecte. En la majoria dels treballs revisats s'ha observat que la falta de suport i calor emocional dels pares s'associa a una autoestima baixa en el nen. Al seu torn, l'autoestima s'ha considerat precursora de nombroses psicopatologies.

\section{Els resultats de la tesi}

L'objectiu de la tesi va ser aplicar aquest model teòric a una mostra representativa de la població clínica infantojuvenil que assistia als centres ambulatoris de salut mental de la província de Barcelona. Van participarhi 185 nens i nenes d'entre 8 i 17 anys i les seves famílies. Els problemes psicològics més prevalents en aquesta mostra van ser els problemes de comportament en el cas dels nens i d'ansietat en el cas de les nenes.

Com a indicadors de problemes socioeconòmics, es van estudiar la presència de problemes econòmics als primers anys de vida del nen, la percepció del nen de l'existència de problemes econòmics actuals, el fet que algun dels pares hagi estat acomiadat de la feina, que algun dels pares estigui a l'atur, el nivell educatiu i el nivell ocupacional (professió) dels pares.

Per analitzar la relació entre aquests indicadors de problemes socioeconòmics, les variables familiars i la psicopatologia en els nens, es van fer servir models d'equacions estructurals. Es tracta d'un procediment estadístic complex que identifica relacions entre variables i diferencia entre relacions directes ( $A$ es relaciona $a m b B$ ) $\mathrm{i}$ indirectes ( $\mathrm{A}$ es relaciona amb $\mathrm{B}$ a través d'una variable mediadora $\mathrm{C}$ ).

A continuació n'exposarem els resultats més relle- vants. La percepció de problemes econòmics actuals i de dificultats econòmiques durant els primers anys de vida del nen afectarien directament la presència de problemes d'ansietat i de l'estat d'ànim en els nens. La percepció dels problemes econòmics de la família o dels limitats recursos (sanitaris, educatius, lleure...) als quals té accés poden generar ansietat o frustració en el nen. Aquest arriba a participar de les preocupacions dels pares sobre els seus problemes financers: es preocupa dels diners disponibles a casa, de les necessitats que no es cobreixen, de les factures impagades o dels problemes a la feina dels adults. Aquesta situació genera estrès i ansietat en el nen i pot estar relacionada amb la presència de simptomatologia ansiosa o depressiva.

L'acomiadament laboral en algun dels pares s'associa en aquest treball a més discòrdia marital, que al seu torn afecta el nivell d'implicació emocional dels pares vers els fills. En aquest cas, no sembla que l'acomiadament laboral guardi relació amb la supervisió o el major control dels pares cap al fill, però sí amb les seves mostres d'afecte, acceptació i comprensió, que podrien veure's reduïdes davant d'aquest problema. Seria aquesta alteració en la forma d'interactuar pares i fills el que afectaria aquests últims, disminuint la seva autoestima o bé incrementant la presència de problemes exterioritzats i interioritzats.

D'altra banda, sembla que els problemes en la relació de parella no afecten directament la salut mental dels nens, però aquesta es pot veure influenciada si la discòrdia marital modifica la forma en què els pares es relacionen amb els seus fills. La discòrdia marital podria tenir un efecte negatiu sobre el grau en què els pares s'impliquen en les activitats dels seus fills i els demostren acceptació i afecte. Seria aquesta alteració en la forma d'interactuar pares i fills la que es relacionaria directament amb la presència de problemes exterioritzats i interioritzats.

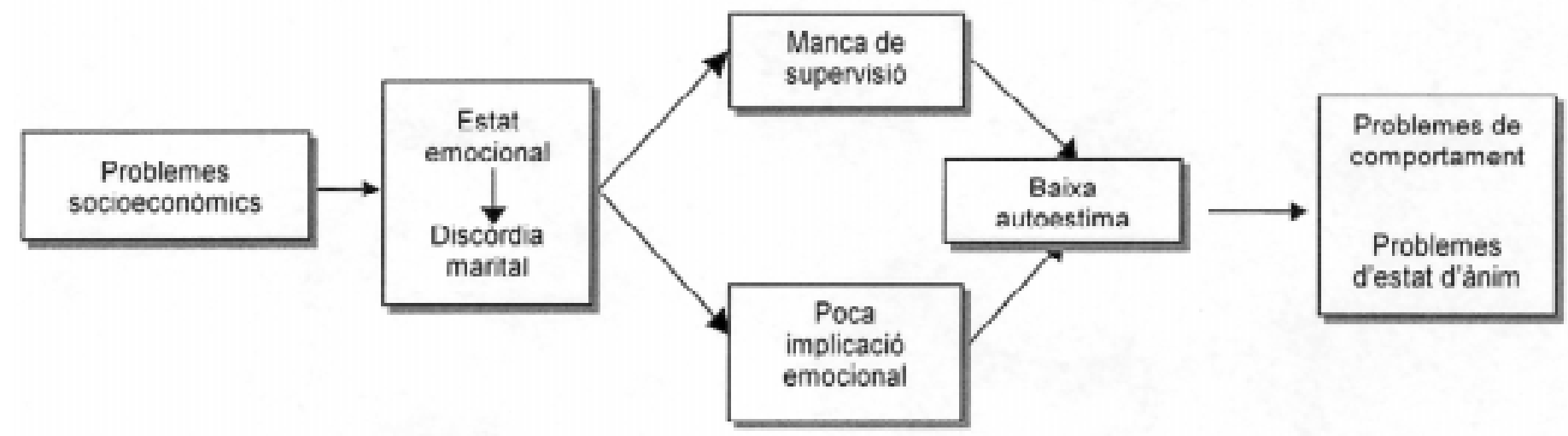

Figura 2. Model teòric general: problemes socioeconòmics, variables familiars, autoestima i salut mental 


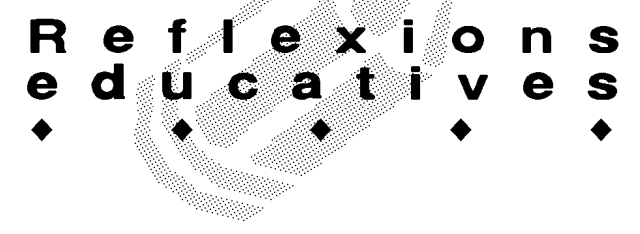

La implicació emocional i la supervisió dels pares s'associen de forma diferent als problemes exterioritzats i interioritzats dels nens. Mentre els problemes exterioritzats semblen estar més influïts tant per la falta de supervisió dels pares com per una baixa calor emocional, els problemes interioritzats es relacionen només amb aquesta última dimensió d'estil educatiu.

Sembla, doncs, que la implicació emocional és una peça clau en aquest entramat, ja que es relaciona directament amb ambdós tipus de psicopatologia i amb una baixa autoestima. Aquest resultat és coincident amb nombrosos estudis que relacionen la falta d'implicació i la poca acceptació i demostracions d'afecte dels pares amb la presència d'una baixa autoestima i de problemes de depressió, ansietat i comportament en els nens. De fet, alguns estudis consideren que la falta de calor i implicació emocional dels pares és més determinant del desenvolupament de problemes psicològics en nens que altres dimensions d'estil educatiu (BRADLEY i CORWYN, 2002; SIMONS, JOHNSON i CONGER, 1994).

\section{I des de l'escola, què podem fer?}

En aquest treball parlem de com els problemes econòmics d'una família afecten la seva dinàmica, i de com la relació entre pares i fills pot veure's perjudicada fins al punt de posar en perill el funcionament socioemocional del nen. Hom es podria preguntar quin paper juguen els mestres en una situació que es desenvolupa principalment a casa, més tenint en compte la tendència que podem tenir grans i petits a "amagar" els problemes de casa i a no voler que ningú s'hi fiqui.

Des de l'escola és important conèixer l'impacte de les dificultats econòmiques que a hores d'ara poden estar patint moltes famílies en el funcionament del nen, ja que podem observar canvis en el funcionament del nen que poden estar, i de fet sovint estan, molt relacionats amb esdeveniments externs al context escolar. Davant un nen que, per exemple, es mostra trist, més callat, que presenta una davallada en el rendiment, que es baralla amb els companys més de l'habitual, caldrà preguntarse, en primer lloc, si té alguna dificultat relacionada amb l'escola que pugui explicar aquest canvi, i en segon lloc, caldrà buscar si aquestes dificultats es poden trobar al context familiar.

Entendre quins poden ser els motius pels quals un nen mostra dificultats en el seu comportament i en el seu rendiment és el primer pas per actuar amb l'objectiu de minimitzar l'impacte dels problemes familiars en ell. Com es pot fer això? Aquí apuntem algunes idees.

Informar els pares dels canvis que s'observen a l'escola.

En el sistema actual, els mestres passen més hores amb els nens que la mateixa família. Això implica que sovint són els mestres els primers a adonar-se de les dificultats o problemes que poden estar experimentant els nens. D'altra banda, els nens d'infantil o de primària no han desenvolupat els recursos suficients per poder fer explícit què els preocupa, i freqüentment expressen els seus problemes en la relació amb els seus iguals, per exemple mostrant-se més irritables o barallant-se més sovint, o a través del seu cos, amb queixes freqüents de mal de panxa o mal de cap. En definitiva, és possible que els nens manifestin els seus problemes de forma encoberta o a través de mecanismes que poden ser més fàcilment detectables en el context escolar i que, en canvi, no siguin tan visibles a casa.

Els pares sotmesos a dificultats econòmiques o problemes laborals o maritals sovint focalitzen la seva atenció en aquests problemes i no es mostren tan atents a les necessitats que en aquells moments poden tenir els fills. És rellevant, doncs, comunicar als pares el que veiem a l'escola i fer-los coneixedors de l'impacte que els seus problemes poden estar tenint en els nens.

Oferir recursos i/o orientació als pares en dificultats.

Moltes famílies no són conscients de l'impacte que els problemes dels adults poden tenir en els més petits, i de com la forma d'educar-los pot influir en el desenvolupament de la seva autoestima, en l'adquisició de recursos que els permeti fer front a les dificultats o en la manifestació de problemes de salut mental.

Sovint, quan un nen té problemes, pares i mestres centrem la nostra atenció en el símptoma, i no en la causa. Si el nen treu males notes o es baralla a classe, el nostre objectiu principal és que millori el rendiment i el comportament, però no ens parem a pensar què pot explicar aquestes dificultats. A la clínica és freqüent observar com els pares porten els nens perquè millorin el comportament a casa, quan la intervenció més adequada passaria per modificar la forma en què els pares es relacionen amb els nens i imposen límits, supervisen les seves activitats o s'impliquen en els seus problemes i necessitats.

Des d'aquesta perspectiva, seria bo que l'escola pogués participar orientant els pares en l'educació dels fills, o bé adreçant-los a serveis externs a l'escola que els puguin oferir recursos per fer front a les seves dificultats. Així, per exemple, freqüentment s'organitzen xerrades adreçades a pares i a mestres des de l'escola o els centres cívics de la zona on es parla de com educar els fills i es donen pautes per millorar la disciplina a casa i a l'escola, o en com fomentar l'autoestima en els més petits. Des de l'escola es pot adreçar als pares a serveis de la xarxa assistencial pública o dels serveis socials que puguin ajudar-los en la seva situació, es pot informar de l'existència de beques i ajudes a l'estudi, etc. 


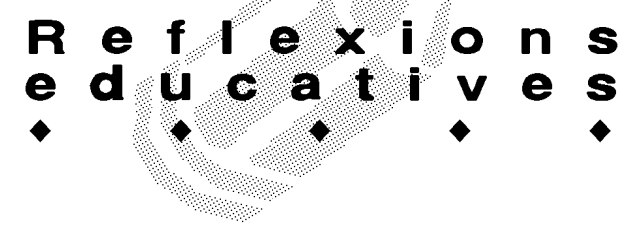

I amb els nens..., què fem a l'escola?

La formació a l'escola no passa únicament per donarlos coneixements i competències curriculars. Els mestres esdevenen agents de salut que de forma implícita o explícita actuen de models de comportament a seguir, i tenen una influència molt important en aquest període del desenvolupament del nen. El nen aprèn a comportar-se no només a casa, sinó també a l'escola, i el que aprèn a casa ho generalitza a classe i viceversa. Per tant, des del context de classe també es pot dedicar un espai a facilitar en els nens l'adquisició d'estratègies efectives d'afrontament davant els problemes i a millorar la seva autoestima.

Algunes idees que poden ajudar els mestres per aconseguir aquest objectiu serien:

1. Oferir la classe com un context on els nens puguin expressar les seves preocupacions, inquietuds i dubtes.

2. Mostrar afecte i acceptació, comprensió i interès davant els problemes dels nens.

3. Oferir suport: els mestres han de comunicar al nen que poden ajudar-lo quan tingui dificultats a les seves tasques escolars.

4. Ajudar-lo a trobar interessos i activitats que li agradin: reforçar i potenciar les seves habilitats. Es tracta de reforçar les habilitats del nen alhora que es treballa per millorar les seves mancances.

5. Corregir-lo quan fa alguna cosa malament: és important que es critiqui la seva actuació, però no la seva forma de ser (GARBER, GARBER i SPIZMAN, 2001). És més adequat "no has fet bé aquests exercicis de mates" que dir "ets un negat per les matemàtiques, ets un gandul...".

6. Reforçar-lo pels seus avenços, valorar com a vàlids els resultats que vagi aconseguint, no exigir perfecció ni rapidesa. A mesura que faci les coses li sortiran millor i més ràpidament.

7. Fomentar en el nen estratègies efectives de resolució de problemes. Per això caldria:

- Valorar un problema com un repte en comptes de com una amenaça.

- Transmetre la idea que els problemes es poden resoldre.

- Transmetre la idea que el nen és capaç de resoldre els problemes.

- Buscar activament solucions.

8. Fomentar la seva autonomia. És important que el nen des de ben petit tingui responsabilitats a l'escola: recollir la seva taula, ajudar el mestre a la classe, etc.

En definitiva, els mestres no han d'esdevenir simples observadors dels problemes que els nens puguin pre- sentar derivats d'esdeveniments externs a l'escola. El seu paper pot ser clau detectant aquestes dificultats $\mathrm{i}$ posant en coneixement dels pares els problemes del nen, alhora que facilitant a grans $\mathrm{i}$ a petits els recursos que puguin tenir a l'abast per fer front a la situació.

\section{Referències bibliogràfiques}

BRADLEY, R.H. i CORWYN, R.F. Socioeconomic status and Child Development. «Annual Review of Psychology», 53 (2002) 371-399.

CONGER, R. D., CONGER, K. J., ELDER, G.H. JR., LORENZ, F. O., SIMONS, R., i WHITBECK, L.B. A family process model of economic hardship and adjustment of early adolescent boys. "Child Development», 63 (1992) 526-541.

CONGER, R. D., CONGER, K. J., ELDER, G.H.JR., LORENZ, F. O., SIMONS, R., i WHITBECK, L.B. Family economic stress and adjustment of early adolescent girls. «Developmental Psychology», 29 (1993) 206-219.

CONGER, R. D., GE, X., ELDER, G.H.JR., LORENZ, F. O., i SIMONS, R. Economic stress, coercive family process, and developmental problems of adolescents. "Child Development», 65 (1994) 541-561.

DUNCAN, G. J. i BROOKS-GUNN, J. Family poverty, welfare reform, and child development. "Child Development», 71 (2000) 188-196.

EUROPA PRESS. El paro y los problemas económicos encabezan los problemas de España por décimo mes, batiendo récords. EUROPA PRESS. [En línia]. [Data de consulta: 1211-2008]. <http://www.europapress.es/nacional/noticia-cisparo-problemas-economicos-encabezan-problemas-espanadecimo-mes-batiendo-records-20081105145846.html>.

GARBER, GARBER i SPIZMAN. Portarse bien. Soluciones prácticas para los problemas comunes de la infancia. Ediciones Medici. Barcelona. 2001.

INSTITUTO NACIONAL DE ESTADÍSTICA. Notas de Prensa. Encuesta de Población Activa (EPA). Tercer trimestre de 2008. [En línia]. [Data de consulta: octubre 2008]. <http:// www.ine.es/daco/daco42/daco4211/epa0308.pdfs.

INSTITUTO NACIONAL DE ESTADÍSTICA. Notas de Prensa. Encuesta de Condiciones de Vida (ECV). 2007. [En línia]. [Data de consulta: novembre 2008]. <http://www.ine.es/prensa/ np526.pdf>.

MCLOYD, V.C. Socioeconomic disadvantage and child development. «American Psychologist», 53 (1998) 185-204.

PARK, J., TURNBULL, A.P., i RUTHERFORD, H. Impacts of poverty on quality of life in families of children with disabilities. «Exceptional Children», 68 (2002), 151-170.

SIMONS, R. L., JOHNSON, C., i CONGER, R. D. Harsh corporal punishment versus quality of parental involvement as an explanation of adolescent maladjustment. «Journal of Marriage and the Family», 56 (1994) 591-607. 